\title{
(2) OPEN ACCESS \\ Model-based economic evaluation of ice cleat distribution programmes for the prevention of outdoor falls among adults from a Swedish societal perspective
}

\author{
Carl Bonander 이 , 1,2 Robin Holmberg 지 , 2,3 Johanna Gustavsson, ${ }^{2,3}$ \\ Mikael Svensson ${ }^{1}$
}

- Additional supplemental material is published online only. To view, please visit the journal online (http://dx.doi. org/10.1136/injuryprev-2021044203).

'School of Public Health and Community Medicine, Institute of Medicine, Sahlgrenska Academy, University of Gothenburg, Gothenburg, Sweden

${ }^{2}$ Centre for Societal Risk Research, Karlstad University, Karlstad, Sweden

${ }^{3}$ Department of Political, Historical and Cultural Studies, Karlstad University, Karlstad, Sweden

\section{Correspondence to} Dr Carl Bonander, School of Public Health and Community Medicine, Institute of Medicine, Sahlgrenska Academy, University of Gothenburg, Goteborg, Västra Götaland Sweden; carl.bonander@gu.se

Received 1 March 2021 Accepted 14 June 2021

\section{ABSTRACT \\ Background Slipping on snow or ice poses a significant health risk among older adults in Sweden. To combat this problem, about 80 Swedish municipalities have distributed ice cleats to older citizens (65+ years old) over the last decade. This paper details a cost- benefit analysis of such programmes.}

Materials and methods We developed a decisionanalytical model to estimate the costs and benefits of ice cleat programmes in Swedish municipalities compared with a business-as-usual scenario. The modelled benefits of the programme were based on effect estimates from previous research, data from population and healthcare registers and a survey of attitudes to and actual ice cleat use. The modelled costs of the programme were based on resource use data collected from 34 municipalities with existing ice cleat programmes. We assessed heterogeneity in the potential impact and benefit-to-cost ratios across all Swedish municipalities as a function of the average number of days with snow cover per year. Uncertainty in the cost-benefit results was assessed using deterministic and probabilistic sensitivity analyses. Results The average benefit-to-cost ratio was 87, ranging from about 40 in low-risk municipalities to 140 in high-risk municipalities, implying that the potential benefits of ice cleat programmes greatly outweigh their costs. Probabilistic and deterministic sensitivity analyses support the robustness of this conclusion to parameter uncertainty and large changes in assumptions about the magnitude of the impact on ice cleat use and injuries. Conclusion The benefits of distributing ice cleats to older adults appear to outweigh the costs from a Swedish societal perspective.

\section{INTRODUCTION}

Pedestrian falls are increasingly being recognised as an important contributor to the burden of transportrelated injuries among older adults. ${ }^{1-3}$ The problem is particularly prominent in colder regions, ${ }^{45}$ where many outdoor falls are caused by icy conditions. ${ }^{67}$ As a low-cost complement to conventional strategies for combatting ice-related injuries during the winter season (eg, snow removal and road salting), about 80 Swedish municipalities have implemented programmes to distribute ice cleats to their older residents at some point in recent years. ${ }^{8}$ Ice cleats can reduce the risk of ice-related falls, ${ }^{9-12}$ and programmes that distribute ice cleats to older adults have the potential to reduce injury rates at the population level, according to a study from Gothenburg (located in the south-west of Sweden). ${ }^{13}$ Despite this, there have been no comprehensive economic evaluations of these programmes covering all Swedish municipalities. While empirical data from Gothenburg suggest that the benefits may outweigh the costs ${ }^{13}$ the impact of these programmes may vary depending on factors related to local climate conditions, such as current ice cleat use and the local risk of snow-related and ice-related fall injuries. This knowledge gap hampers the possibility for informed decisions about implementing ice cleat distribution programmes elsewhere.

Model-based economic evaluations can help bridge the gap between available empirical evidence and local circumstances that affect the potential impact of an intervention. ${ }^{14}$ In this study, we develop a decision-analytical model to estimate the impact of ice cleat distribution programmes depending on local climate conditions and apply the model to conduct a cost-benefit analysis of ice cleat programmes in the context of all Swedish municipalities.

\section{MATERIALS AND METHODS}

\section{Setting, location and target population}

Swedish municipalities are local, self-governing authorities funded by municipal-level income taxes. They are responsible for providing several essential public services at the local level, including local traffic safety interventions. There are 290 municipalities in Sweden, with population sizes varying from about 2000 to 975000 according to population data from Statistics Sweden. In 2019, we sent out an electronic survey to all Swedish municipalities to collect data on ice cleat programmes. Out of the 228 responses we received, 78 reported having distributed ice cleats at some point during the last decade (four before 2012 and the rest after). Most provided ice cleats (free of charge) to any citizen above the age of 65 years old. We therefore focus on this population in our study.

We also collected data on the number of purchased and distributed ice cleats and resource use (ie, costs) associated with existing programmes. The distribution data show that about $90 \%$ of all purchased ice cleats were distributed. Not all 
Table 1 Model parameters, probability distributions and data sources for the decision-analytical model for economic evaluation of municipal ice cleat distribution programmes

\begin{tabular}{|c|c|c|c|c|}
\hline Parameter & Average (range, if applicable) & SE & $\begin{array}{l}\text { Distribution (probabilistic } \\
\text { sensitivity analysis) }\end{array}$ & Data source \\
\hline $\begin{array}{l}\text { Annual number of snow- } \\
\text { related or ice-related fall } \\
\text { injuries at baseline as a } \\
\text { function of population size and } \\
\text { climate }\left(y_{j}\right)\end{array}$ & $21.6(2.7,472.6)$ & $\begin{array}{l}\text { Municipality-specific SE } \\
\text { from regression prediction }\end{array}$ & Lognormal & $\begin{array}{l}\text { Municipality-specific and age-specific data from } \\
\text { National Patient Register }{ }^{21} \text {. Population data } \\
\text { from Statistics Sweden }{ }^{30} \text {. Annual number of } \\
\text { snow days from the Swedish Meteorological and } \\
\text { Hydrological Institute* }\end{array}$ \\
\hline $\begin{array}{l}\text { Initial change in ice cleat use } \\
\text { as a function of climate }\left(\theta_{j}\right)\end{array}$ & $0.25(0.09,0.35)$ & $\begin{array}{l}\text { Municipality-specific SE } \\
\text { from regression prediction }\end{array}$ & Logit-normal & $\begin{array}{l}\text { National survey (random sample, } n=4608 \text { aged } \\
65+\text { ) conducted in } 2007 \text { by the Swedish Civil } \\
\text { Contingencies Agency* }\end{array}$ \\
\hline $\begin{array}{l}\text { Compliance over time, }\left\{\omega_{1},\right. \\
\text { multiplicative scaling factor } \\
\left(\omega_{t}\right)\end{array}$ & $\left\{\cdot \omega_{5}\right\}=\{1,0.75,0.50,0.25,0\}$ & Not available & None & $\begin{array}{l}\text { Calibrated }{ }^{*} \text { simulation model to results from } \\
\text { quasi-experimental evaluation in Gothenburg }\end{array}$ \\
\hline $\begin{array}{l}\text { Effect of ice cleat use (RR), } \\
\text { log scale }\end{array}$ & -0.799 & 0.333 & Lognormal & $\begin{array}{l}\text { Randomised controlled trial }{ }^{12}, \mathrm{RR}=0.45(95 \% \mathrm{Cl} \text { : } \\
0.23 \text { to } 0.85) \dagger\end{array}$ \\
\hline $\begin{array}{l}\text { Total programme cost per } \\
\text { purchased ice cleat pair in } \\
2018 \text { Euros }(c) \text {, log scale }\end{array}$ & 1.998 & 0.100 & Lognormal & $\begin{array}{l}\text { Electronic survey sent to all Swedish } \\
\text { municipalities ( } n=34 \text { responses with cost data)* }\end{array}$ \\
\hline $\begin{array}{l}\text { Benefit per averted injury in } \\
2018 \text { Euros }\end{array}$ & 329783 & Not available & None & Swedish Transport Administration ${ }^{17}$ \\
\hline
\end{tabular}

*Additional information on data and estimation is provided in the online supplemental file.

TRR for falls (with or without an injurious outcome). Estimate for injurious falls was 0.1 ( $95 \% \mathrm{Cl}: 0.02$ to 0.53 ) but was only based on a total of 11 events (one in the treatment group and 10 in the control group). Our preferred estimate (for falls) is supported by more data and is more conservative.

$\mathrm{RR}$, relative risk.

municipalities purchased one pair per citizen; in terms of population coverage, the distribution rates imply that the programmes reached roughly $40 \%$ of the targeted age group in the average municipality.

\section{Study design}

We developed a decision-analytical model to estimate the costs and benefits of implementing an ice cleat distribution programme in a specific municipality $j$ compared with a business-as-usual scenario. The model synthesises previous research with estimates presented in this paper to perform a population impact analysis. ${ }^{15}$ The impact analysis provides a way to estimate the potential effect of increasing ice cleat use in a population with varying input parameters that depend on local climate conditions. Table 1 provides an overview of the base-case inputs for the model and data sources used in the present investigation. The next section provides an overview of the decision-analytical model and our empirical analyses. The online supplemental file provides additional details on the data sources and estimation strategies. Analyses were performed in R, V.4.0.2. ${ }^{16}$

\section{Human subjects statement}

This study used anonymised, non-sensitive data and aggregate health data from secondary sources. No human subjects were directly involved.

\section{Decision-analytical model}

We used the following model to estimate the net present value (NPV) of an ice cleat distribution programme in municipality $j$ over the period $t=1,2, \ldots, T$ :

$$
N P V_{i}=\left\{\sum_{t=1}^{T} \frac{1}{(1+r)^{t}}\left[b\left(y_{j t}\left(\frac{\omega_{t} \theta_{j}(1 / R R-1)}{1+\omega_{t} \theta_{j}(1 / R R-1)}\right)\right)\right]\right\}-c N_{i},
$$

where $t$ denotes time in years from baseline and $r$ is the discount rate for future benefits (we used 3.5\% per year as recommended by the Swedish Transport Administration ${ }^{17}$ ). The first term in Equation (1) measures the total monetary benefit of the programme. Several parameters determine the benefit of the programme, including the assumed monetary benefit per averted injury, denoted by $b$, and the assumed impact of the programme on the number of snow-related and ice-related fall injuries at year $t$, which is given by

$$
y_{i t}\left(\frac{\omega_{t} \theta_{j}(1 / R R-1)}{1+\omega_{t} \theta_{j}(1 / R R-1)}\right)
$$

Equation (2) can be used to estimate the impact of reducing the prevalence of a risk factor in a population. ${ }^{18}$ In our case, the risk factor is the lack of ice cleat use during icy weather conditions. In Equation (2), $y_{j t}$ is the annual number of older adults $(65+$ years old) injured due to snow-related or ice-related falls in municipality $j ; 1 / R R$ is the multiplicative inverse of the causal risk ratio of ice cleat use on the risk of outdoor fall injuries, and the term $\omega_{t} \theta_{j}$ is the causal effect of the programme on the proportion of ice cleat users, where $\theta_{j}$ is the initial change and $\omega_{t}$ is a scaling factor used to model the longevity of the behaviour change. We used data from a randomised trial of the effects of ice cleats as an estimate of the causal effect of ice cleats (relative risk $(\mathrm{RR})=0.45$; table 1$).^{12}$

\section{Estimation of effects on behaviour}

The most challenging aspect to estimate is the effect of ice cleat programmes on ice cleat use, as there is no direct evidence on the effects of these programmes on behaviours. We do not believe that the share of collected ice cleats (90\%) would be a good proxy for behaviour change, because a large share of the individuals who collected a pair may already own and use ice cleats. To obtain a reasonable approximation for the initial behaviour change $\theta_{i}$, we instead relied on data from a national survey conducted by the Swedish Civil Contingencies Agency in 2007 that collected data on ice cleat use and attitudes towards ice cleats ( $n$ aged above 65 years old $=4608$; see online supplemental file for details). The data also contained information on the respondents' municipality of residence, which enabled 
the matching of local climate data to each respondent. As indirectly supported by behaviour change theory, ${ }^{19}$ we assumed that non-users (respondents who reported that they do not use ice cleats during icy conditions) with a positive attitude towards the efficacy of ice cleats ('I believe that ice cleats are important or very important for increasing my safety during slippery road conditions') would be susceptible to change when presented with the option to collect a free pair of ice cleats. On average, $25 \%$ of the respondents fit this category, which we refer to as potential compliers. We note that this may be seen as an upper bound for the actual share of new ice cleat users; we therefore also conducted scenario analyses with lower assumed compliance rates (see below). We used a binary indicator for potential compliers as the outcome in a logistic generalised additive mode ${ }^{20}$ to establish a model for the share of potential compliers in municipality $j$ as a smooth function of the average number of snow days per year (provided by the Swedish Meteorological and Hydrological Institute). The model results are presented in online supplemental table S2 and figure S6.

To estimate the temporal variation in compliance (ie, the scaling factor $\omega_{t}$ in Equation (1)), we calibrated our model to quasi-experimental estimates from Gothenburg, which found evidence of a short-lived effect on injury rates $(-45 \%$ during the first year and $-10 \%$ over a 4 -year period ${ }^{13}$; see online supplemental file for calculations). Our calculations assume that this temporal dynamic is driven by a reduction in the effect of the programme on ice cleat use over time. Specifically, we modelled a relatively short-lived effect on behaviour that decreases monotonically over time and disappears completely after 4 years (table 1). We also considered a scenario where the effect is limited to the first year only.

\section{Estimation of baseline injury rates}

We modelled the annual number of persons treated for icerelated fall injuries at inpatient or outpatient facilities (International Classification of Diseases, 10th Revision, external case code: W00) at baseline, $y_{i t}$, as a smooth function of local climate (average number of days with snow cover per year) and population size using a negative binomial generalised additive model. ${ }^{20}$ We used age-specific and municipality-specific data from the Swedish National Patient Register ${ }^{21}$ between the periods 2008 and 2017, provided to us in aggregate form (ie, a total for the entire period) by the National Board of Health and Welfare. The model results are presented in online supplemental table S1 and figure S4. To estimate year-to-year variability around the municipality-specific means in our simulations, we relied on relative variation around the mean annual number of hospitalisations due to snow-related or ice-related falls at the national level (online supplemental figure S5). Overall, 61810 persons (aged $65+$ years old) were treated for snow-related or ice-related fall during the included period (municipal average: 21.6 injuries per year; table 1). Given the low fatality risk related to snow-related or ice-related falls, we only considered the benefits from averting non-fatal injuries (only 30 deaths in the age group $65+$ years old occurred between 20082017 in Sweden).

\section{Estimation of the monetary benefit per averted injury}

To convert the expected effect of the programme on injury rates into monetary terms, we relied on the estimated monetary benefit per averted pedestrian fall injury used by the Swedish Transport Administration (€329 783), ${ }^{17}$ which is based on a combination of material costs ( $€ 3592$, eg, healthcare utilisation, transportation costs and informal care by family members) and the willingness to pay (WTP) per averted injury (€326 191). ${ }^{17}$ The WTP is intended to reflect the utility loss from the injured individual's physical and psychological suffering in monetary terms. Thus, the overall benefit estimate captures both qualityof-life gains and averted material costs to society. Their estimate was obtained by taking the product of the WTP per qualityadjusted life years (QALY) (based on a stated preference survey $(\mathrm{n}=880)$ related to fatal and non-fatal traffic-related injuries, conducted in Sweden ${ }^{22}$ ) and the expected QALY loss per pedestrian fall injury from a remaining life-time perspective (1.387 QALYs according to data from a sample of pedestrians injured in pedestrian falls in Sweden (mean age: 64 years; $n=256)^{23}$ ) and then adding the estimated material costs per pedestrian fall injury to that estimate (based on the same study as the QALY estimates, ${ }^{23}$ although we subtracted the estimated production loss for this study as our target population is above the retirement age in Sweden; see online supplemental file for details).

\section{Estimation of program costs}

The final term in Equation (1) determines the total cost of the programme (including administration costs), which is given by the product of the total programme cost per purchased ice cleat pair, $c$, and the number of purchased ice cleat pairs. To model the municipality-specific programme cost, we assumed that each municipality purchases one pair of ice cleats for each citizen aged $65+$ years old $\left(N_{i}\right.$ in Equation (1)). To estimate the programme cost per ice cleat pair, we used data from 34 municipalities that reported cost and procurement data in our survey. The average reported programme cost was $€ 8.73$ per ice cleat pair (range: 2.35-27.37). Following Bonander and Holmberg, ${ }^{13}$ we assumed that the majority of the programme costs occur at year one in conjunction with the procurement of ice cleats.

\section{Economic evaluation}

The evaluation assumes a societal perspective, that is, it includes costs across all societal sectors in the valuation of material costs (including healthcare utilisation, administration costs, material damage to property and informal care) and WTP per averted injury. ${ }^{17}$ Our programme cost estimates are intended to reflect the total programme costs from a municipal perspective (including the procurement and distribution of ice cleats, administration and communication). We estimated the total NPV summed over all municipalities in Sweden and studied heterogeneity in effectiveness depending on climate conditions. The results are presented in 2018 Euros, converted from 2018 Swedish kronor (SEK) assuming the 31 December 2018 exchange rate (€0.09811 per SEK).

\section{Sensitivity analyses}

We used both deterministic and probabilistic sensitivity analyses to assess uncertainty. ${ }^{24}$ The parameter estimates, SEs and assumed distributions are presented in table 1 .

In the probabilistic sensitivity analysis, we ran 100000 simulations per municipality and used the proportion of simulations that resulted in a positive NPV to estimate the probability that an ice cleat programme would be cost-beneficial in municipality $j$.

In the deterministic sensitivity analysis, we varied key parameters as described in table 2. We also considered a pessimistic scenario in which we doubled the programme costs, restricted the longevity of the effect to 1 year and halved the assumed increase in ice cleat users and the effect of ice cleats compared with the base-case scenario. 
Table 2 Results from the deterministic sensitivity analysis

\begin{tabular}{|c|c|c|c|}
\hline Scenario & $\begin{array}{l}\text { Expected NPV } \\
\text { (in million Euros) }\end{array}$ & Benefit-to-cost ratio & $\begin{array}{l}\operatorname{Pr}(\text { cost-beneficial) } \\
\text { mean (min-max) }\end{array}$ \\
\hline Base-case result (for reference) & $1192.62(1061.77,1338.12)$ & $87.44(77.69,98.31)$ & $0.991(0.989,0.992)$ \\
\hline Increase cost to highest reported cost per procured ice cleat ( $€ 27.9$ per pair) & $1141.55(1012.03,1286.41)$ & $23.55(20.93,26.49)$ & $0.988(0.981,0.99)$ \\
\hline Reduce WTP per QALY gained to match healthcare sector ( $€ 50000$ per QALY) & $245.25(217.05,276.71)$ & $18.98(16.85,21.35)$ & $0.987(0.977,0.989)$ \\
\hline $\begin{array}{l}\text { Reduce baseline risk by a factor of } 0.59 \text { to match warmest year between } 2001 \text { and } \\
2019\end{array}$ & $688.77(611.34,774.01)$ & $51.5(45.72,57.89)$ & $0.990(0.987,0.991)$ \\
\hline Reduce initial compliance rate from $25 \%$ to $5 \%$ on average & $281.86(245.93,325.25)$ & $21.66(18.96,24.91)$ & $0.986(0.978,0.989)$ \\
\hline Reduce $R R$ of ice cleat use by half $(R R=0.73)$ & $405.86(361.81,453.98)$ & $30.75(27.44,34.38)$ & $0.989(0.985,0.991)$ \\
\hline Reduce RR of ice cleat use by three quarters $(\mathrm{RR}=0.875)$ & $166.5(148.28,186.02)$ & $13.21(11.82,14.69)$ & $0.985(0.974,0.988)$ \\
\hline Limit intervention effect to first year & $443.49(391.82,502.75)$ & $33.51(29.64,37.93)$ & $0.989(0.985,0.991)$ \\
\hline Increase discount rate to $5 \%$ & $1160.59(1032.03,1303.57)$ & $86.09(76.49,96.80)$ & $0.991(0.989,0.992)$ \\
\hline Cost-minimisation analysis (ignore WTP per averted injury) & $-0.65(-1.76,0.62)$ & $0.95(0.85,1.07)$ & $0.405(0.004,0.720)$ \\
\hline
\end{tabular}

The table shows the results from additional scenarios to test the sensitivity of the base-case results to deterministic variations in key assumptions and input parameters. Details and rationale for each scenario is presented in the online supplemental file to this article. The estimates in the table reflect totals or means for all Swedish municipalities averaged across 100000 simulations, with the 2.5th and 97.5 th percentiles of the simulated estimates in parentheses unless otherwise noted. The simulations are run over a 4-year period. The net present value (NPV) is given by Equation (1), which, if positive, implies that the interventions are cost-beneficial. The benefit-to-cost ratio expresses how much the estimated benefits outweigh the costs in relative terms. Pr(cost-beneficial) is the proportion of the 100000 simulations in which the NPV is positive, which gives an overall estimate of how likely it is that an ice cleat programme would be cost-beneficial according to the model (for this parameter, the numbers in parentheses reflect the least to most certain municipal-specific estimate).

Pr, probability; QALY, quality-adjusted life years; RR, relative risk; WTP, willingness to pay.

Given the conceptual uncertainty regarding our estimates of the share of potential compliers, we also performed a breakeven analysis for each municipality to estimate the minimal required share of the target population who would need to start using ice cleats for the programme to be cost-beneficial. We obtained this number by solving for the non-negative compliance share that minimises the square of Equation (1) (ie, results in an NPV that is approximately zero) using a box-constrained optimisation algorithm implemented in the optimx package for $\mathrm{R}^{25}$

\section{RESULTS}

In the base-case scenario, the results show a 15 percentage point increase in the number of ice cleat users over 4 years, resulting in a $15 \%$ reduction in snow-related or ice-related fall injuries over the same period. In the pessimistic scenario, the expected change in ice cleat users is only 3 percentage points, with a $1 \%$ reduction in injuries. Due to low intervention costs, the results from both the base-case and the pessimistic scenarios showed a positive expected NPV in all Swedish municipalities, with municipalityspecific percentages of simulations with a positive NPV ranging from $98.9 \%$ to $99.2 \%$ in the base-case scenario and $67.5 \%$ to $96.3 \%$ in the pessimistic scenario (table 3).

The average benefit-to-cost ratio was 87.4. This number varied from approximately 40 in southern municipalities to 140 in some of the northern parts of Sweden (figure 1A), in a geographical pattern that closely follows that of snow-related or ice-related fall injury rates per person-year (figure 1B). Our data suggest that the number of potential compliers is lower in the north due to higher baseline ice cleat use in high-risk municipalities (figure 1C,D). This indicates that there is a risk of ceiling

Table 3 Results from the cost-benefit analysis under base-case and pessimistic scenarios in which ice cleat programmes are implemented in all Swedish municipalities compared with a business-as-usual scenario without ice cleat programmes

\begin{tabular}{lcc}
\hline Estimate & Base-case* & Pessimistic scenario† \\
\hline Incremental benefit, total (million Euros) & $1192.62(1061.77,1338.12)$ & $89.16(78.05,101.09)$ \\
\hline Incremental cost, total (million Euros) & $13.64(13.35,13.94)$ & $27.28(26.70,27.88)$ \\
Net present value, total (million Euros) & $1178.98(1048.42,1324.18)$ & $61.89(52.35,73.21)$ \\
Benefit-to-cost ratio & $87.44(77.69,98.31)$ & $3.27(2.89,3.71)$ \\
Percentage point change in ice cleat users over 4 years, mean & $15.02(14.96,15.09)$ & $3.00(2.99,3.02)$ \\
Expected number of injuries without programmes, total & $25192(24436,26008)$ & $25192(24440,26009)$ \\
Expected number of injuries with programmes, total & $21441(20681,22253)$ & $24921(24176,25731)$ \\
Injuries averted, total & $3751(3339,4209)$ & $270(240,307)$ \\
Relative intervention effect (rate ratio) & $0.85(0.83,0.87)$ & $0.99(0.99,0.99)$ \\
Absolute intervention effect (rate difference, 100000 person-years) & $-50.96(-45.36,-57.18)$ & $-3.67(-3.26,4.17)$ \\
\hline Pr(cost-beneficial), mean (min-max) & $0.991(0.989,0.992)$ & $0.915(0.675,0.963)$ \\
\hline
\end{tabular}

The estimates in the table reflect totals or means for all Swedish municipalities averaged across 100000 simulations, with the 2.5th and 97.5 th percentiles of the simulated estimates in parentheses unless otherwise noted. The simulations are run over a 4-year period. The incremental benefits and costs reflect differences between a scenario where all municipalities have implemented ice cleat programmes versus a business-as-usual scenario. The net present value (NPV) is given by Equation (1), which, if positive, implies that the interventions are cost-beneficial. The benefit-to-cost ratio expresses how much the estimated benefits outweigh the costs in relative terms. The remaining estimates reflect estimated effects on the average change in ice cleat users and on injury rates. Pr(cost-beneficial) is the proportion of the 100000 simulations in which the NPV is positive, which gives an overall estimate of how likely it is that an ice cleat programme would be cost-beneficial according to the model (for this parameter, the numbers in parentheses reflect the least to most certain municipal-specific estimate).

${ }^{*}$ Scenario using the best available estimates from table 1.

tDoubled costs, increase in ice cleat use limited to the first year, halved initial compliance and halved effect of ice cleats (compared with the base-case scenario). 

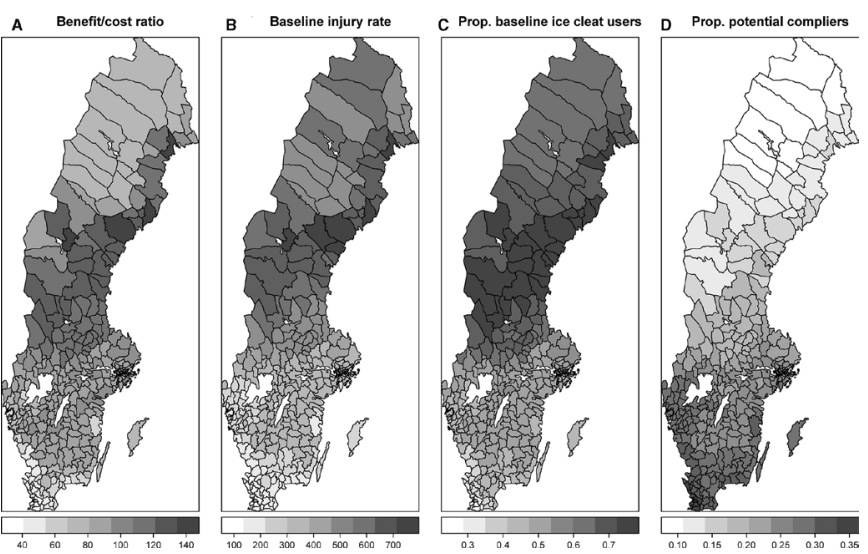

Figure 1 Maps of Sweden's 290 municipalities that illustrate the geographical variation in (A) estimated benefit-to-cost ratios from our economic simulations (base-case scenario), (B) baseline snowrelated or ice-related fall injury rates per 100000 person-years, (C) the estimated proportion of ice cleat users per municipality without ice cleat distribution programmes and (D) the estimated proportion of the population susceptible to change as a consequence of an ice cleat distribution programme (non-users with a positive attitude towards the efficacy of ice cleats).

effects concerning the magnitude of the behaviour change that could be brought about by ice cleat programmes in some areas. However, given the high injury rates in this region, our model still expects that the economic benefits of an ice cleat programme would be the largest in these municipalities.

\section{Deterministic sensitivity analyses}

We constructed a set of scenarios, each presented in table 2, to probe the sensitivity of the results to changes in key parameters (their rationale and additional details are provided in the online supplemental file). In addition to these scenarios, we also conducted a cost-minimisation analysis that ignores the valuation of health benefits (ie, the WTP per injury averted) and compares only the material costs averted to the cost of the programme. The results from these analyses are presented in table 2 . Although the expected NPV varies greatly in magnitude when we modify parameters related to the expected monetary benefit per injury averted and effects of the ice cleat programmes, each costbenefit-related scenario still indicates a positive expected NPV. The cost-minimisation analysis implies that ice cleat programmes are almost cost-neutral even if we ignore the monetary valuation of health benefits, although the total material costs are likely to increase slightly compared with a business-as-usual scenario.

\section{Breakeven analysis}

The breakeven analysis showed that at least $0.15 \%$ of the population would need to start using ice cleats for a programme to be cost-beneficial in the average municipality (range: $0.038 \%-$ $0.465 \%$ ), which implies that at least one person would need to start using ice cleats per approximately 670 purchased pairs for an ice cleat programme to be beneficial in expectation. In terms of injury rates, the estimated breakeven point is one injury averted per 37800 purchased ice cleat pairs.

\section{DISCUSSION}

Pedestrian falls are underprioritised in road safety policy despite their considerable contribution to the burden of transportrelated injuries. ${ }^{23}$ One reason may be that decision-makers are reluctant to implement population-based programmes due to a lack of evidence on their effectiveness. ${ }^{18}$ Our study implies that ice cleat distribution programmes can be an effective method to reduce ice-related falls, which is a major cause of outdoor fall injuries in the Nordic countries and regions with similar climates. $^{4512}$ The results suggest that the implementation of ice cleat distribution programmes would be cost-beneficial for Swedish municipalities, which is also supported by an empirical study from Gothenburg. ${ }^{13}$ We can now extend this conclusion to the entirety of Sweden, which supports the programmes already implemented in 78 Swedish municipalities and suggests that the remaining municipalities should consider distributing ice cleats to older adults.

A key strength of our study is the use of a model-based design grounded in high-quality data, which allowed us to thoroughly examine the potential benefits of ice cleat programmes in all Swedish municipalities under multiple realistic scenarios. That said, the study also has several noteworthy limitations. Our main concern is the estimated effect of ice cleat programmes on ice cleat use, which may be overstated. Despite this potential source of bias, our sensitivity and breakeven analyses suggest that an ice cleat distribution programme would have to be almost completely ineffective (affecting only one person per 670 targeted individuals) for it not to be cost-beneficial, which appears unlikely given previous research on ice cleats and ice cleat distribution programmes, ${ }^{1912}{ }^{13}$ as well as general research on behaviour change interventions on health and safety behaviours. ${ }^{26}$ Even so, it is important to continue monitoring and evaluating the impact of ice cleat programmes with empirical evaluation designs. However, the non-randomised nature of the implementation of these programmes presents a challenge for credible evaluation. ${ }^{13}$ Our model, which relies partly on data from a randomised trial, ${ }^{12}$ offers a way to assess the potential impacts of ice cleat programmes without reliance on the strong assumptions required for a causal interpretation of non-randomised data. ${ }^{27}$

This study only included the potential benefits of ice cleat programmes on injury outcomes. Access to ice cleats may also increase walking, ${ }^{9}$ which suggests that ice cleat programmes may have other health benefits that are not included in our estimates. ${ }^{28}$ Further, the economic data reflect a Swedish societal perspective. We expect that the conclusions may extend

\section{What is already known on the subject}

- Icy weather conditions are a major cause of outdoor fall injuries in colder regions.

- Ice cleats can reduce the risk of injurious falls during icy conditions.

- Distribution programmes may increase usage and reduce injury rates among older adults.

\section{What this study adds}

- This is the first comprehensive economic evaluation of ice cleat programmes.

- We model effects depending on local climate in Swedish municipalities.

- The potential benefit of distributing ice cleats to older adults outweighs the costs. 
to countries with similar climates, but the context dependency of economic data may still warrant replication in other countries before drawing a conclusion on the transferability of the results. ${ }^{29}$ Additional research is also needed to assess how these programmes can be most effectively designed to combat the potential reduction in compliance over time.

\section{CONCLUSION}

The potential benefits of distributing ice cleats free of charge to older adults appear to greatly outweigh the costs. Our results imply that the municipalities that have already implemented these programmes should continue to provide ice cleats. The remaining municipalities should consider implementing ice cleat distribution programmes.

Funding This work was supported by a research grant from Familjen Kamprads Stiftelse (grant number 20180067)

Map disclaimer The depiction of boundaries on the map(s) in this article does not imply the expression of any opinion whatsoever on the part of BMJ (or any member of its group) concerning the legal status of any country, territory, jurisdiction or area or of its authorities. The maps are provided without any warranty of any kind, either express or implied.

\section{Competing interests None declared.}

Patient consent for publication Not required.

Ethics approval The data used in this study reflect anonymised, non-sensitive information or aggregate health data from public and administrative data sources, which are exempt from the need for ethical approval according to the Swedish law of research ethics. Nonetheless, ethical approval was sought and approved by the Regional Ethics Board in Uppsala (DNR 2018/480, with addendum (DNR 202110338) approved by the Swedish Ethical Review Authority).

Provenance and peer review Not commissioned; externally peer reviewed.

Data availability statement Data are available upon reasonable request. Contact the corresponding author for details.

Supplemental material This content has been supplied by the author(s). It has not been vetted by BMJ Publishing Group Limited (BMJ) and may not have been peer-reviewed. Any opinions or recommendations discussed are solely those of the author(s) and are not endorsed by BMJ. BMJ disclaims all liability and responsibility arising from any reliance placed on the content. Where the content includes any translated material, BMJ does not warrant the accuracy and reliability of the translations (including but not limited to local regulations, clinical guidelines, terminology, drug names and drug dosages), and is not responsible for any error and/or omissions arising from translation and adaptation or otherwise.

Open access This is an open access article distributed in accordance with the Creative Commons Attribution Non Commercial (CC BY-NC 4.0) license, which permits others to distribute, remix, adapt, build upon this work non-commercially, and license their derivative works on different terms, provided the original work is properly cited, appropriate credit is given, any changes made indicated, and the use is non-commercial. See: http://creativecommons.org/licenses/by-nc/4.0/.

\section{ORCID iDs}

Carl Bonander http://orcid.org/0000-0002-1189-9950

Robin Holmberg http://orcid.org/0000-0001-5637-0359

\section{REFERENCES}

1 Schepers P, den Brinker B, Methorst R, et al. Pedestrian falls: a review of the literature and future research directions. J Safety Res 2017;62:227-34.

2 Oxley J, O'Hern S, Burtt D, et al. Falling while walking: a hidden contributor to pedestrian injury. Accid Anal Prev 2018;114:77-82.

3 Methorst R, Schepers P, Christie N, et al. 'Pedestrian falls' as necessary addition to the current definition of traffic crashes for improved public health policies. J Transp Health 2017;6:10-12.

4 Elvik R, Bjørnskau T. Risk of pedestrian falls in Oslo, Norway: relation to age, gender and walking surface condition. J Transp Health 2019;12:359-70.
5 Gyllencreutz L, Björnstig J, Rolfsman E, et al. Outdoor pedestrian fall-related injuries among Swedish senior citizens--injuries and preventive strategies. Scand I Caring Sci 2015;29:225-33.

6 Björnstig U, Björnstig J, Dahlgren A. Slipping on ice and snow--elderly women and young men are typical victims. Accid Anal Prev 1997;29:211-5.

7 Berntman M. Fotgängares olyckor och skador i trafikmiljö med fokus på fallolyckor. Bulletin 295 / 3000 2015;Bulletin 295. Available: http://lup.lub.lu.se/record/8194779 [Accessed 2 Feb 2021].

8 Holmberg R, Gustavsson J, Bonander C. Evaluation of the design and implementation of municipal ice cleat distribution programs for the prevention of a ICE-related fall injuries among older adults in Sweden. PLOS ONE 2021.

9 Berggård G, Johansson C. Pedestrians in wintertime-effects of using anti-slip devices. Accid Anal Prev 2010;42:1199-204.

10 Gard G, Berggård G. Assessment of anti-slip devices from healthy individuals in different ages walking on slippery surfaces. Appl Ergon 2006;37:177-86.

11 Gard G, Lundborg G. Test of Swedish anti-skid devices on five different slippery surfaces. Accid Anal Prev 2001;33:1-8.

12 McKiernan FE. A simple gait-stabilizing device reduces outdoor falls and nonserious injurious falls in fall-prone older people during the winter. J Am Geriatr Soc 2005;53:943-7.

13 Bonander C, Holmberg R. Estimating the effects of a studded footwear subsidy program on pedestrian falls among older adults in Gothenburg, Sweden. Accid Anal Prev 2019;132:105282.

14 Siebert U. When should decision-analytic modeling be used in the economic evaluation of health care? The European Journal of Health Economics 2003:4:143-50.

15 Verma A, Torun P, Harris E, et al. Population impact analysis: a framework for assessing the population impact of a risk or intervention. J Public Health 2012;34:83-9

16 R Core Team. R: a language and environment for statistical computing. Vienna, Austria: R Foundation for Statistical Computing, 2020. https://www.R-project.org/

17 The Swedish Transport Administration. Analysmetod och samhällsekonomiska kalkylvärden för transportsektorn, 2020. Available: https:/wwww.trafikverket.se/ contentassets/4b1c1005597d47bda386d81dd3444b24/asek-7-hela-rapporten_ 210129.pdf [Accessed 18 Feb 2021].

18 Heller RF, Buchan I, Edwards R, et al. Communicating risks at the population level: application of population impact numbers. BMJ 2003;327:1162-5.

19 Gielen AC, Sleet D. Application of behavior-change theories and methods to injury prevention. Epidemiol Rev 2003;25:65-76.

20 Wood SN. Fast stable restricted maximum likelihood and marginal likelihood estimation of semiparametric generalized linear models. Journal of the Royal Statistical Society Series B 2011;73:3-36.

21 Ludvigsson JF, Andersson E, Ekbom A, et al. External review and validation of the Swedish national inpatient register. BMC Public Health 2011;11:450.

22 Olofsson S, Persson U, Hultkrantz L. Betalningsviljan för att minska risken för icke-dödliga och dödliga skador I samband Med vägtrafikolyckor - en studie Med kedje-ansats. Lund: Lund University, 2016. https://ihe.se/publicering/betalningsviljanatt-minska-risken-icke-dodliga-och-dodliga-skador-samband-med-vagtrafikolyckor-enstudie-med-kedje-ansats/

23 Olofsson S, Gralén K, Macheridis K. Personskadekostnader och livskvalitetsförlust till följd AV vägtrafikolyckor och fotgängarolyckor singel. Sammanfattning AV resultat. Lund: Lund University, 2016. https://ihe.se/publicering/sammanfattningpersonskadekostnader-och-livskvalitetsforlust/

24 Briggs AH, Weinstein MC, Fenwick EAL, et al. Model parameter estimation and uncertainty: a report of the ISPOR-SMDM Modeling Good Research Practices Task Force--6. Value Health 2012;15:835-42.

25 Nash JC, Varadhan R. Unifying Optimization Algorithms to Aid Software System Users: optimx for R. J Stat Softw 2011;43:1-14.

26 Anker AE, Feeley TH, McCracken B, et al. Measuring the effectiveness of Mass-Mediated health campaigns through meta-analysis. $J$ Health Commun 2016;21:439-56

27 Angrist JD, Pischke J-S. Mostly Harmless Econometrics: An Empiricist's Companion. 1st edn. Princeton: Princeton University Press, 2009.

28 Lee I-M, Buchner DM. The importance of walking to public health. Med Sci Sports Exerc 2008:40:5512-8.

29 Shields GE, Elvidge J. Challenges in synthesising cost-effectiveness estimates. Syst Rev 2020;9:289.

30 Ludvigsson JF, Almqvist C, Bonamy A-KE, et al. Registers of the Swedish total population and their use in medical research. Eur J Epidemiol 2016;31:125-36. 